Publicación semestral. ISSN 2215-4906

Volumen 81 - Número 1 Julio - Diciembre 2021

\title{
Tierra, maíz, agua: los elementos originarios del planeta en el Arte contemporáneo mesoamericano
}

\author{
Earth, corn, water: the original elements \\ of the planet in contemporary Mesoamerican Art
}

Luis Fernando Quirós Valverde

DOI 10.15517/es.v81i1.47655

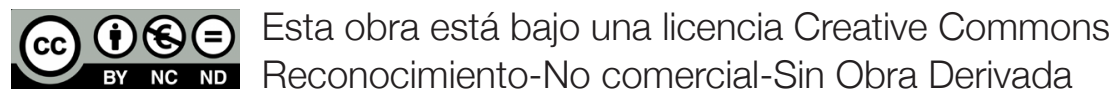


Tierra, maíz, agua: los elementos originarios del planeta en el Arte contemporáneo mesoamericano

\title{
Earth, corn, water: the original elements
} of the planet in contemporary Mesoamerican Art

\author{
Luis Fernando Quirós Valverde ${ }^{1}$ \\ Investigador independiente \\ San José, Costa Rica
}

Recibido: 12 de febrero de $2021 \quad$ Aprobado: 26 de marzo de 2021

1 Profesor jubilado del Instituto Tecnológico de Costa Rica y de la Universidad de Costa Rica. Pintor, posee estudios en Artes Plásticas. Correo electrónico: luquiva@gmail.com 


\section{Introducción}

El ensayo introduce aspectos culturales, conceptuales, teóricos y geográficos que enmarcan la zona denominada Mesoamérica. Esta se comprende como la zona que va desde el sur de México, Belice, Guatemala, El Salvador, Honduras, Nicaragua hasta el norte de Costa Rica, reunidas por su herencia cultural originaria, en particular la maya.

En el marco de esta comprensión se encuentra el colectivo de arte contemporáneo Museo de Pobre \& Trabajador, creado en 2019. Es un proyecto privado que nace durante la crisis de la COVID-19 y la cuarentena del 2020, como un espacio virtual para potenciar la cultura y abordar problemáticas del arte de la periferia y emergente en esta región. Para junio-agosto 2021, se expone Mesoamérica Tierra Encendida, muestra de arte actual en la Sala Umbral, Museo de Jade y la Cultura Precolombina, con 45 artistas del ámbito focalizado, curada por la mexicana Erandi Ávalos, la nicaragüense Illimani de los Andes y Luis Fernando Quirós.

\section{Contextualización}

Importa, en esta perspectiva, observar la tierra y el agua como abordaje al arte contemporáneo; los frutos que emanan de los procesos agrícolas, los cuales nos distinguen como región (tan solo recuérdese la etiqueta de Banana's Republic, o, "hombres de maíz"). Entonces, nos referiremos precisamente a aquella semilla sagrada, como elemento milenario en la alimentación mesoamericana, con la cual la población prepara recetas que enriquecen la gastronomía originaria y/o popular. Además, interesan las herramientas, la tecnología agrícola, y las problemáticas o afectaciones al suelo, todo aquello que contribuye a sacarle provecho a estos frutos donados por la naturaleza.

La tierra es portadora de un elemento sacro, se habla de la diosa madre en la filosofía clásica, la "madre universal" en la India, o la "pacha mama" en la cosmovisión de los pueblos originarios de América, en tanto surte alimentos, recursos naturales, pero también talento para cultivarla y diseñar herramientas. Importa recordar que, al morir, reposamos simbólicamente en ese vientre o regazo, recubiertos por su piel de tierra para volver a ella.

Trabajar con esta materia para la obra de arte implica respeto, en tanto se elabora con el suelo donde se recoge alimento, desde tiempos inmemoriales. Hay algo de sagrado en su uso, y el mismo terreno brinda el lenguaje a recurrir: lo áspero y agrietado conlleva un lenguaje; si se mezcla la tierra con agua se convierte en lodo, barro, arcilla, con el grado de 
Tierra, maíz, agua: los elementos originarios del planeta

Reflexión

en el Arte contemporáneo mesoamericano

plasticidad propio del material que se hace moldeable; modelable entre las manos del alfarero, para obtener objetos de uso hogareño. Es una materia que en la mayoría de casos experimenta pasar por el fuego (otro elemento o recurso del planeta), que lo materializa con un nuevo carácter, propiedades táctiles, audibles, funcionales, estéticas o incluso espirituales.

\section{Metodología de la investigación}

Para llegar a las conclusiones expresadas en este estudio, las entrevistas practicadas a los artistas fueron publicadas en mi blog personal Árbol Dardo. Cito partes de estas en tanto arrojan retroalimentación, comentarios, además de considerar críticas importantes que estimulan a reflexionar y apreciar la validez del presente ensayo.

\section{Escenario a observar}

Durante el tiempo de sequía en Guanacaste, Costa Rica, frontera sur de Mesoamérica, extensa planicie extendida a lo largo y ancho del golfo de Nicoya, el terreno se agrieta formando gruesos terrones, ásperos y secos, como la vida de los habitantes ante tantas adversidades y vicisitudes sufridas en el presente. Los agricultores que sembraron maíz para la tortilla, para la rosquilla, o el tamal de maíz pisque, principales alimentos de la zona, al cosechar -debido a la sequía, o por lo contrario a la inundación-, a veces solo recogen mazorcas con unos cuantos granos. Los "Hombres de maíz", parte de la tradición regional particularmente de la cultura maya, se frustran cuando a esta faja terrestre que llamamos istmo lo invade la incertidumbre, la carencia de empleo, el hambre, y grupos migratorios que bajan al sur o se dirigen al norte buscan reacomodar tantas presiones, cargas a sus necesidades o condición humana.

El abordaje de estos simbolismos de la materia terrestre y sus frutos, a través del trabajo crítico creativo que aportan los artistas analizados y focalizados en este ensayo, permite mostrar que actividades como la agricultura requieren otras aguas que regeneren el suelo, además de mayor investigación para mejorar dicha tecnología. Purga, además, el historial de terratenientes que se apoderaron de extensas fincas y al campesino originario o agrario solo le quedaron pequeñas parcelas, sin agua, en condiciones muy severas, que desalienta la tradición mesoamericana de sacarle frutos a la tierra.

ESCENA. Revista de las artes, 2021, Vol. 81, Núm. 1 (julio-diciembre), pp. 435-464 
Es relevante, entonces, la conexión, entre el suelo y los productos, la práctica agrícola, y el entorno o paisaje para el arte actual. Este va a ser situado o visto de distintas maneras y visiones por parte del colectivo de artistas que conforman esta focalización: Carlos Aguilar (Cuba-México), los Hermanos Poyón (Guatemala), Josué Orellana (Honduras), Illimani de los Andes (Nicaragua), Stephanie Williams (Costa Rica), Diana Barquero (Costa Rica), Mariela Richmond (Costa Rica) y José Rosales (Costa Rica). La artista Illimani de los Andes comenta sobre esta relación:

Desde el Génesis hasta el Popol Vuh se invoca a la tierra. El polvo y el barro; el inicio y el fin. El camino fallido por encontrar vida al producir hombres de barro, que solo fueron posibles de ser, por medio del maíz, quea diferencia del cristianismotiene de base la manzana como sinónimo de "pecado" y "expulsión", sin embargo, [en] nuestra ideología sincrética, ese es el mito que nos inunda (I. de los Andes, Comunicación personal, 5 de agosto de 2020).

Entonces, pachamama es la idea de una "diosa dadora" como ya se afirmó. Da la materia, pero también la experiencia de trabajar la tierra y el talento para cohesionar las tecnologías agrícolas, para sacarle el maíz a la tierra. Importa aclarar que existe una tecnología que permite extraer el fruto a la tierra fértil, que produce ganancias al agricultor, al país y a la región; pero también es importante saber elaborar alimentos sanos a partir del producto, pues hoy inunda el mercado alimentario el llamado "alimento chatarra".

\section{Problemática de la región}

Años atrás, en la década de los años setenta del siglo XX, en la región central a este abordaje -particularmente en la zona de Guanacaste-, los gobiernos de turno propiciaron la tala y devastación de la montaña para fomentar la ganadería, y buscar el mercado de carnes para la exportación. Sin embargo, talar el bosque acrecentó la sequía. El ganado debía caminar enormes distancias buscando mejores pastos e hidratarse, resultaba una carne nervuda, no apta para las hamburguesas de las compañías filibusteras de comida chatarra, que penetraron a nuestras ciudades generando transculturización.

Considerando la historia, antes de la llegada de los españoles, ese fragmento del territorio mesoamericano poseía parajes boscosos, con grandes arboledas que refrescaban la sensación térmica del clima. Bajo las frondosas copas de los árboles nativos del sitio, corrían riachuelos sin contaminar, abundantes en peces, camarones, langostinos; la cacería 
Tierra, maíz, agua: los elementos originarios del planeta

Reflexión

en el Arte contemporáneo mesoamericano

era oportuna por la cantidad de animales silvestres y un medio reproductivo natural eficaz. Solo había algunos parajes a cielo abierto para cultivar el maíz, semilla sagrada en el corazón de la tierra que además del agua requieren la luz del Sol. El historiador Luis Ferrero, habla de las riquezas de la ecología que encontraron las tribus migrantes del Norte de Mesoamérica:

Estas se efectuaron por el corredor transitable que era la costa del Pacífico de América Central, donde se encontraron condiciones ecológicas más favorables que las de la costa Atlántica. Aquella tiene fértiles llanuras aluviales cruzadas por numerosos arroyos que descienden de las montañas. Entradas, lagunas, manglares y bosquecillos puntean la costa. Aguaceros leves, clima cálido, con gran potencial agrícola, y riqueza mineral caracterizan esta zona (Ferrero, 2000, p. 98).

La condición climática oportuna motivó el tránsito, los desplazamientos, las movilidades y las migraciones en Centroamérica y México, las cuales ha sido ampliamente estudiadas en la actualidad. El sociólogo Abelardo Morales expresa al respecto:

La región centroamericana es un pequeño territorio, fragmentado a su vez en pequeños territorios pertenecientes a distintas naciones, pero también en otros territorios supranacionales, articulados en torno a distintas territorialidades, por ejemplo, las regiones trasfronterizas o territorios étnicos. Cómo istmo geográfico, Centroamérica ha sido siempre un puente para el tránsito intercontinental, y por la existencia de redes basadas en vínculos históricos entre sus pueblos, la movilidad persiste y se integra a las nuevas expresiones de la movilidad transnacional (Hoffmann \& Morales, 2018, pp. 43-44).

Algo ocurrió también con las tierras del Caribe, a inicios del siglo XX, después de la irracional explotación por parte de la United Fruit Company. Carlos Luis Fallas, en su novela Mamita Yunai (1941), escribió un párrafo que clarifica la acelerada explotación:

Pero al poco tiempo la tierra se cansó de dar bananos y ya el cacao no significó nada para los yanquis. Entonces estos levantaron sus rieles, destruyeron los puentes y, después de escupir con desprecio sobre la tierra exhausta, se marcharon triunfalmente hacia otras tierras de conquista (Fallas, 1998, p. 70).

Este ensayo repasa las prácticas artísticas actuales en el contexto de las tendencias del arte de la tierra, abstracción áspera o terrosa que evoca los signos de materias terrestres. Calzan en esta perspectiva artistas residentes en la región mesoamericana 
quienes focalizan este simbolismo apreciado en las estratificaciones internas del planeta, en las profundidades marinas, los humedales, lagos, lagunas y ríos, como también en la capa vegetal del suelo que lo recubre, que hace germinar un contenido vital abundante. El enfoque apunta a caracterizar y analizar su trabajo creativo y lo que los reúne en el colectivo. La reflexión apunta a caracterizar y analizar.

\section{Referentes artísticos con el abordaje de la tierra}

Muestras de arte anteriores como Mesótica Il: Centroamérica, re-generación (1996), del Museo de Arte y Diseño Contemporáneo (MADC), co-curada por Virginia Pérez-Ratton (1950-2010) y Rolando Castellón (1937), introduce lenguajes ásperos, críticos, de impronta política. Esto reafirmó una beta estilística disiente, no contemplativa sino de activa interacción con la tierra; carácter cultivado con los años en el arte emergente de esta región. Suma a este ámbito otra importante muestra: Estrecho Dudoso (2006) presentada en el MADC, curada por Pérez-Ratton y Tamara Díaz.

Importa a este nivel determinar referentes regionales que utilizan el barro en sus distintas manifestaciones, con lo que amplían un lenguaje genuino dentro de arte originario de la región. Entre otros, se menciona a Juan Luis Rodríguez Sibaja, Héctor Burke, Álvaro Gómez, Isabel Ruiz (Guatemala), Regina Aguilar (Honduras), Raúl Quintanilla (Nicaragua), quienes demuestran dominio de este elemento material, como es el caso de Rolando Castellón en su muestra RASTROS, expuesta en la Sala 1 del MADC durante el 2005, curada por Ernesto Calvo.

Respecto al maestro Castellón, Paulo Herkenhoff, curador internacional, quien fuera director de la Bienal de Sao Paulo y curador para Latinoamérica del Museo de Arte Moderno de Nueva York (MOMA), explica en un extenso texto sobre la obra de Rolando

Producir la obra de arte significa para él transportar un conjunto de dispositivos durables para engendrar prácticas artísticas en una estructura que es la obra, pero no puede necesariamente limitarse a su frágil físico. Puede el artista articular el poder simbólico al límite (Herkenhoff, 2007, p. 27). 
Tierra, maíz, agua: los elementos originarios del planeta

Reflexión

en el Arte contemporáneo mesoamericano

En este mismo libro, la curadora Virginia Pérez-Ratton agrega su perspeción sobre el trabajo del maestro Rolando Castellón:

Hay que saber lo que huele la tierra apisonada, humedecida y barrida cuidadosamente, los trazos que la escoba de millo puede dejar al barrerla y quitarle el exceso de polvo para dejarla lucia, hay que imaginar lo que los elementos naturales significan más allá de su función esencial como partes de un todo, para llegar a la profundidad de su valor simbólico (Pérez-Ratton en Herkenhoff, 2007, p. 77).

\section{Carácter de abordajes actuales}

Hoy en día, algunos los artistas interactúan con la materia origen del planeta: la tierra, lodo, piedra, lo vegetal (plantas ornamentales o comestibles), árboles, troncos, bejucos, hojas, cortezas, maderas, tejidos, piedras, arenas, cenizas. Sin exceptuar a los demás elementos como el agua, el fuego, la atmósfera, el mundo marino, los humedales, lagos y lagunas. La interacción es para la explotación tolerante de sus frutos, obtenidos mediante siembras agrícolas, recolección de recursos naturales y, en el terreno del arte, para la elaboración simbólica de sus lenguajes y discursos por medio de cantos, poesía, danzas, fotografías, narrativas, teatro, entre otras áreas de la cultura.

Se dice que hacer arte hoy es un ejercicio creativo muy distinto al realizado en el pasado. Anteriormente, al artista le importó la contemplación y la representación fiel del entorno en el cuadro. En ello se centra gran parte de la tradición pictórica del paisaje valle-montañoso y costero en la región. Las personas artistas en el arte contemporáneo elaboran el paisaje transformándolo creativamente: en el land art, la resultante es un nuevo paisaje, se transforma según la sensibilidad e investigación del artista. Para la historiadora y teórica del arte, Karin Thomas: "En el land art los espacios naturales y también los paisajes alterados industrialmente, se convierten en material de configuración artística" (Thomas, 1978, p. 39).

Con esta categoría de transformación del entorno se estimula la totalidad de sentidos: tacto, oído, olfato, vista y también el espacio, el campo, el bosque, el mar, ríos, lagos

y humedales. Esos espacios donde va a ser contemplada la obra, la cual generalmente se encuentra en el mismo entorno que los materiales a utilizar. Este singular encaje es fundamental, de aprovechar in situ los materiales del entorno, pero también la enmarca como manifestación efímera.

ESCENA. Revista de las artes, 2021, Vol. 81, Núm. 1 (julio-diciembre), pp. 435-464 
En otro diedro del panorama artístico actual, en materia del posible uso de la tierra en el arte encontramos el ejemplo del francés Pierre Huyghe. Este artista creó en un espacio bajo techo de grandes dimensiones y lo logró introduciendo tierra, agua, piedras, materias ásperas y ordinarias sobre la superficie de concreto o piso, con lo que imprimió -según mi pensamiento crítico- una aterradora monumentalidad a la intervención artística, que visualiza un mundo en constante construcción, donde el individuo se aprecia diminuto y la materia lo invade, se le viene encima como terraplén. En otras propuestas, el artista introduce una enorme y espesa capa de naturaleza: plantas, musgos, ramajes, que igual parecen disminuir o minimizar lo humano. Se trata de una monumentalidad que se aprecia en el arte oriental respecto a la naturaleza. El artista pinta una naturaleza encabritada, amenazante, quizás, y eso redunda en el respeto que el ser humano siente por la naturaleza.

La materia, en el arte povera [arte pobre]², considera observar este carácter de materiales, hojarascas, tejidos gruesos o ásperos, maderas, palos, piedras, arenas, cuerdas, con lo que observa los cambios producidos en el tiempo. Estos son, en general y como se mencionó, efímeros, pues el interés se centra en la documentación de tales procesos.

Interesa, además, la cromática y superficies del arte povera, que sugieren apreciar elementos de la tierra, observados en las capas tectónicas del planeta, paredes de roca o en las profundidades marinas; como también importa el mundo vegetal, las plantas, los bejucos, las hojas, los tallos, el vivir en la tierra o en el aire. Pondera un rico universo simbólico a observar, extraer y el tener una experiencia crítica con su lenguaje. Quizás, lo importante hoy en día es que la experiencia no se quede únicamente en la representación, sino que se logre interactuar creativamente con estos dones del planeta.

\section{Territorio y prácticas artísticas mesoamericanas}

La curadora y crítica de arte Virginia Pérez-Ratton, en el ensayo "Estrecho Dudoso", -título de una muestra definitoria y referente, realizada en 2006, que ocupó el Museo de Arte y Diseño Contemporáneo y varios otros espacios expositivos de la capital San José- advertía esas nociones de incertidumbre en esta faja terrestre, la cual reúne dos grandes masas continentales. De esta manera, introduce Pérez-Ratton su ensayo:

2 Impulsado en Italia por Germano Celant en la segunda parte de la década de los setenta del siglo pasado, y quien recién falleció en la ciudad de Milán, víctima del COVID-19. 
Tierra, maíz, agua: los elementos originarios del planeta

Reflexión

en el Arte contemporáneo mesoamericano

La región centroamericana, esa franja de tierra que algunos llaman cintura y que otros consideran dudosa, ha sido desde siempre objeto de deseo, tanto de los individuos que se han acercado a sus hermosas y traidoras costas, como de los grandes poderes de cada época. Al igual que el Caribe, ha sido escenario de tentaciones, equívocos, confusiones y construcciones míticas (Pérez- Ratton, 2012, p. 39).

\section{Colectivos y comunidades en el istmo}

Estos abordajes sobre un territorio y materia origen, la tierra y el agua con sus productos, aglutina a un colectivo de artistas que, aunque no se reúnan físicamente a exponer, investigar y experimentar con la materia, trabajan conformando visualizaciones que se traslapan incluso con conflictos y adversidades de la cultura, el territorio, la naturaleza, la política. El presente ensayo equivale a plantear una curaduría, donde se pretende aunar un cuerpo de manifestaciones que entroncan con el abordaje y se explora de tal manera que cada artista muestre las fortalezas de lo suyo.

Al observar dicho territorio áspero -como los terrones agrietados por falta de agua y la búsqueda de recursos influida por presiones y choques culturales, sociales, políticos- se intenta apreciar tales fenómenos territoriales e influencias del poder, para hacer fuerte el discurso artístico que parte del material. Aunque el suelo es uno, que reúne tierra desde México al resto de América Central, se incluye también otro de los elementos esenciales del planeta: el agua. Con ella se incorporan los humedales, ríos, lagos y mares, en tanto al mezclarse con la tierra produce el lodo, la arcilla para fabricar utensilios funcionales y/o artísticos.

Esta simbólica de elementos originarios del planeta fue tratada por nuestros ancestros originarios y el arte hoy lo rememora. De esta forma, se enmienda la táctica de reflexionar sobre la memoria regional, con un repaso del arte de algunos artistas que enlisto a continuación: Carlos Aguilar, cubano radicado en México; los hermanos Ángel y Fernando Poyón, de Guatemala; el hondureño Josué Orellana; la nicaragüense Illimani de los Andes; los costarricenses Stephanie Williams, Mariela Richmond, Diana Barquero, Alessandro Valerio, José Rosales y Yamil de la Paz García. Estos artistas elevan esos productos culturales como forma de conciencia, la cual señala que sin tierra, sin maíz, sin banano, sin agua, no habrá pueblo como tampoco noción de identidad. 


\section{Carlos Aguilar: acecho de la sinapsis}

Carlos Aguilar (1984) es migrante cubano. Estudió en el Instituto Superior de Arte de La Habana, donde inicia la investigación artística y docencia. Se traslada a Cancún, México, interesado en aprender y emprender con el tradicional uso del barro en el arte originario mesoamericano. Observa una investigación con la materia origen, la tierra, discurso de la fragmentación y desintegración del objeto, en particular, hecho de arcilla.

Imagen 1. "Acecho de la sinapsis" (2018). Proceso fotográfico de performance
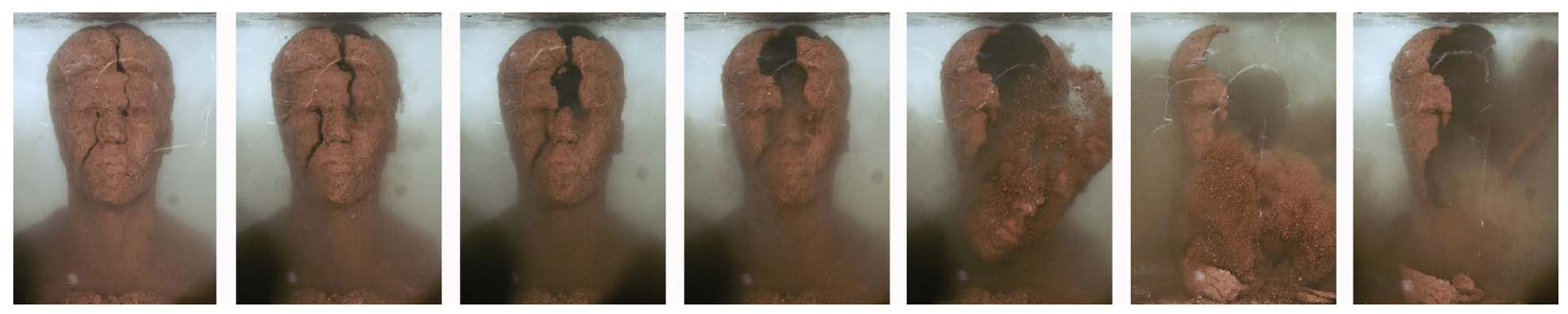

Fuente: Carlos Aguilar.

Para "Acecho de la sinapsis" (2018) el artista utiliza un autorretrato en barro (sin ser quemado en el horno), para luego ser sumergido en un recipiente de vidrio con agua. La tierra transformada en arcilla, sin aún ser cocida al fuego, al introducirse en el líquido, en tanto manifestación física o concreta, se destruye.A mi pregunta acerca del significado del uso de la tierra en su obra, Aguilar responde:

Para mí como ciudadano cubano, la tierra es un material de una gran carga histórica... ... y pensar la tierra como una materia cargada de contenidos diversos: Isla, territorio, situación geográfica e intereses geopolíticos, conquistas, colonización, exterminio edénico, procesos de aculturación y transculturación, cultivo, esclavitud, sometimiento y lucha por la liberación nacional, régimen totalitario, comunismo, experimentación social, procesos de migración (Quirós, 11 de junio de 2020, párr. 8). 
Tierra, maíz, agua: los elementos originarios del planeta

Reflexión

en el Arte contemporáneo mesoamericano

\section{Los hermanos Fernando y Ángel Poyón: fortalezas, cuadratura y linaje de la cultura maya}

En el panorama del arte contemporáneo centroamericano brilla el pensamiento y obra de dos hermanos originarios, oriundos de San Juan Comalapa, pueblo kaqchikel, del departamento de Chimaltenango, Guatemala. Ambos son artistas de gran visibilidad en el panorama internacional del arte actual.

Para Aguilar, de Cuba/México, la tierra es materia de experimentación para vencer la incertidumbre a través de la investigación acerca de la física del material. Por su parte, los hermanos guatemaltecos observan dichas fortalezas de la cultura maya, presente en el significado por la tierra y el maíz.

En la muestra virtual del Museo de Pobre \& Trabajador, titulada Tierra \& Arte Contemporáneo (2020), con una propuesta land art de Fernando Quirós, apreciamos eras, surcos, acomodamiento de objetos utilizados en los cultivos. El azadón, la sacha, pico y pala son herramientas físicas y lenguaje de sus instalaciones, pero también herramientas del pensamiento crítico que rivaliza con todo aquello que encasille o demarque un territorio.

Una pieza expuesta por Ángel Poyón (1976) en esta muestra fue un tejido que adosan los pobladores para cargar la leña o los productos agrícolas. Sobre el tejido dispuso una capa de tierra, peinado con los dedos de sus manos, referenciando aquel decir popular "siembra con las uñas" y devela esas contingencias del agro.

Imagen 2. "Peinar la tierra" (2018) performance

En "Peinar la tierra con las uñas. Zurcos Tapäl (mecapal de maguey) Tierra y maguey" (2020) explica que el Tapäl (mecapal) es una herramienta que sirve para cargar bultos sobre la espalda y que está hecho de una faja de tejido de maguey que tiene sogas en sus extremos y se apoya en la frente. En "Peinar la tierra con las uñas 2. Zurcos Awäxab'äl (semillero de

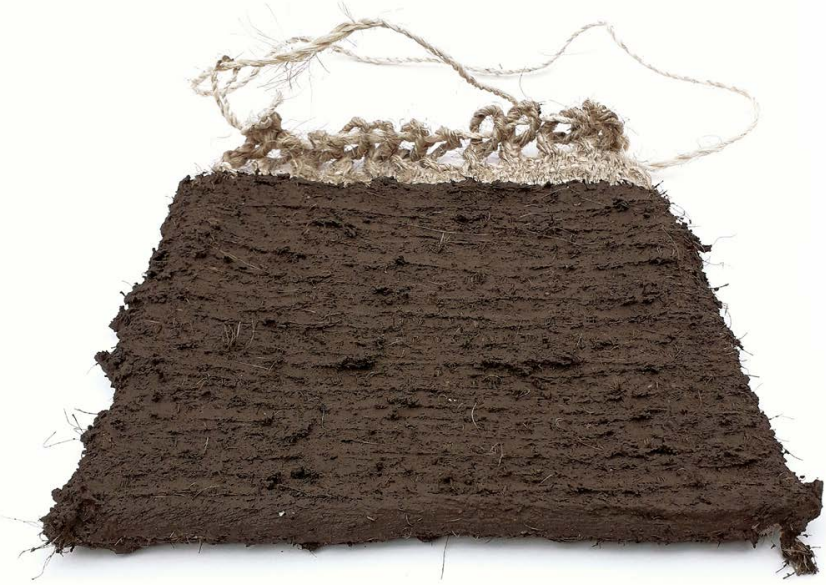

Fuente: Ángel Poyón. 
maguey y tierra) (2020), el artista aclara que Awäxab’äl (semillero) es el bolso tipo cangrejo utilizado para llevar las semillas durante la siembra. Otra de las obras del artista guatemalteco son los jícaros metáfora del mundo: Chi q'acho, Chi q'axe'el, [a nuestra casa, a nuestra raíz] (2014). Productos o frutos de la naturaleza, leídos con el pensamiento y en busca de una conexión con el espíritu original. También expone "Najïk ri ulew chi ixk'äq, k’a xkek'ototäj na ri ab'äj [Peinar la tierra con las uñas, hasta desenterrar la piedra/la memoria]" (2020), que es una pieza en la cual usa la tierra sobre una piedra de moler.

Fernando Poyón (1982) focaliza el visor hacia los males que afectan la ecología del planeta, la deforestación de las selvas y bosques naturales. Observa las herramientas y de manera lúdica introduce agentes conceptuales que motivan a reflexionar. Una piedra

Imagen 3. "Land art" (2020)

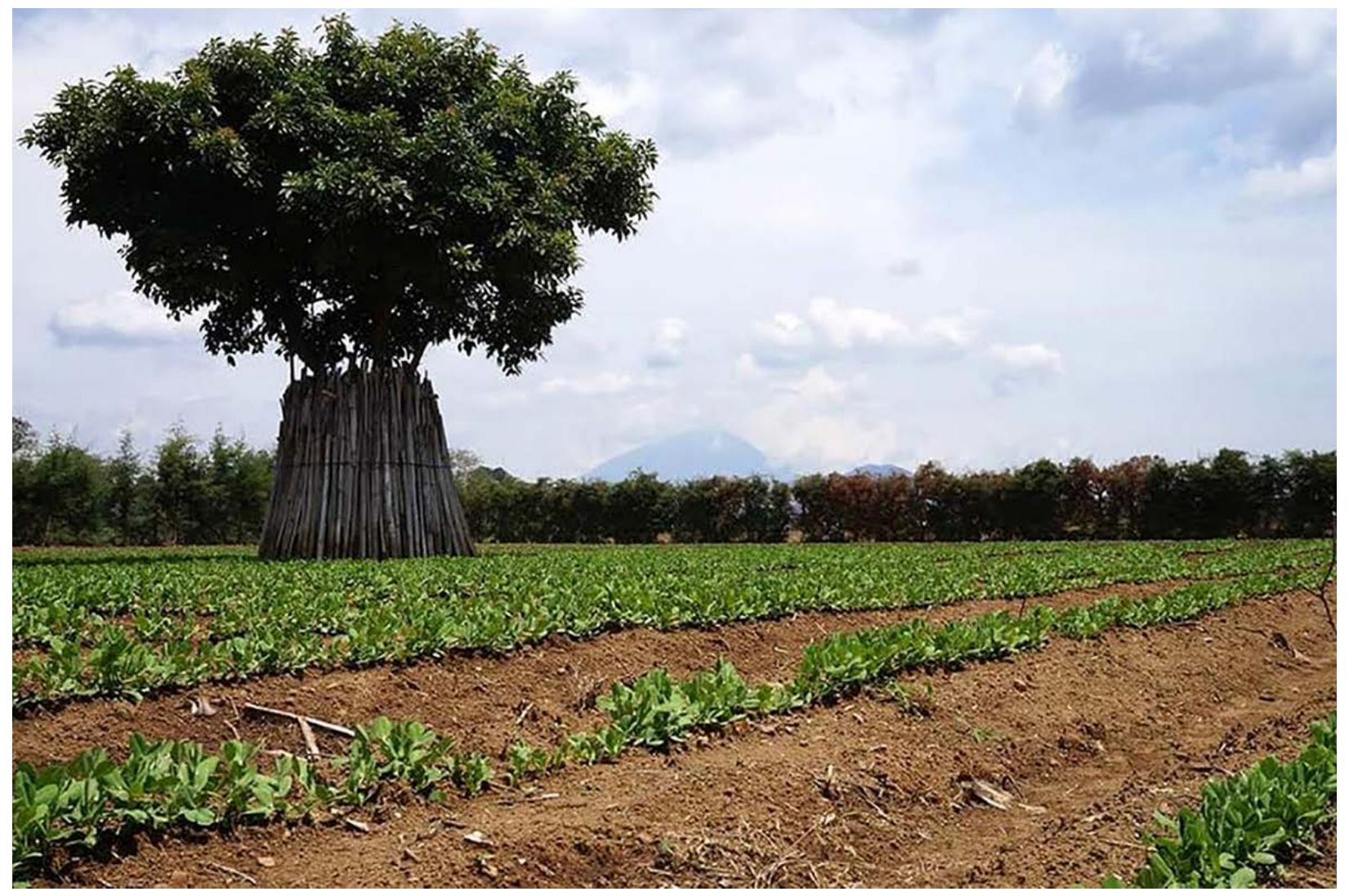

Fuente: Fernando Poyón

ESCENA. Revista de las artes, 2021, Vol. 81, Núm. 1 (julio-diciembre), pp. 435-464 
Tierra, maíz, agua: los elementos originarios del planeta

Reflexión

en el Arte contemporáneo mesoamericano

de gran tamaño, con la cartografía del mundo grabada con tecnología láser, titulada "EI sitio" (2010) es, en su percepción, bordes fronterizos condicionados por otros lenguajes o costumbres. Son discursos de caminantes, migrantes, pueblos que buscan otras tierras, desplazamientos que empezaron a ser sensibles y claman por atención en el contexto del arte actual (Quirós, 2019).

\section{Josué Orellana: adobar la tierra}

El hondureño Josué Orellana (1993) es un artista emergente que elabora un gesto fogoso, juguetón, jovial, pero también crítico. Trabaja con instalaciones y performances e imprime una carga poética hacia las plantas comestibles, medicinales, y ornamentales. Usa la tierra como arcilla sin cocer, para configurar pelotas de barro o símbolos efímeros. Anteriormente, comenté de su trabajo en el catálogo de la muestra virtual Josué Orellana. Adobar la tierra: "Implica -como lo hace el polluelo al romper desde dentro el cascarón para emerger al mundo- romper la tierra, deseo del artista de trasgredir, y sacar de su innata actitud creativa, su aguijón" (Museo de pobre, 2020, p. 7). Cité, para el texto de ese catálogo a Bataille acerca de la contradicción humana:

Así, a través de los cambios, volvemos a encontrar la oposición entre la plétora del ser que se desgarra y se pierde en la continuidad y la voluntad de duración del individuo aislado. Si llega a faltar la posibilidad de transgresión, surge entonces la profanación" (Bataille, 2005, p.146).

En una de sus acciones más dramáticas sostiene entre sus manos un corazón modelado por él en tierra. Se trata de pelotas toscas, terrones sin ninguna pretensión estética, sembrados con ramitas de orégano o flores veraniegas, para adobar la tierra y esperar, quizás, su regeneración. Sin embargo, eso encuentra eco en los discursos contemporáneos que elaboran dicha poética. 
Imagen 4. "Adobar la tierra" (2020) fotoperformance

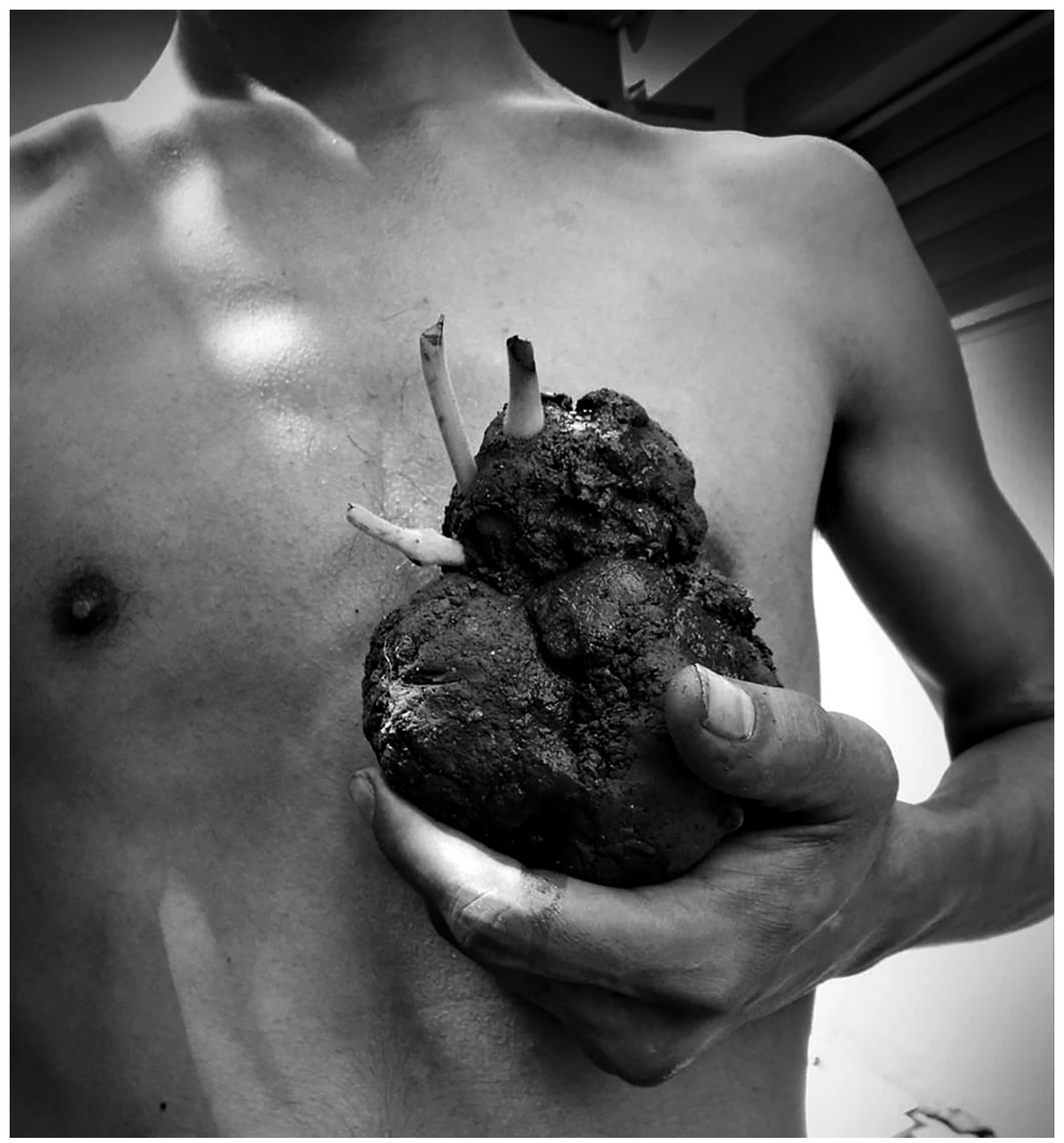

Fuente: Josué Orellana.

ESCENA. Revista de las artes, 2021, Vol. 81, Núm. 1 (julio-diciembre), pp. 435-464 
Tierra, maíz, agua: los elementos originarios del planeta

Reflexión

en el Arte contemporáneo mesoamericano

Imagen 5. "Lágrimas de flores" (2017) performance
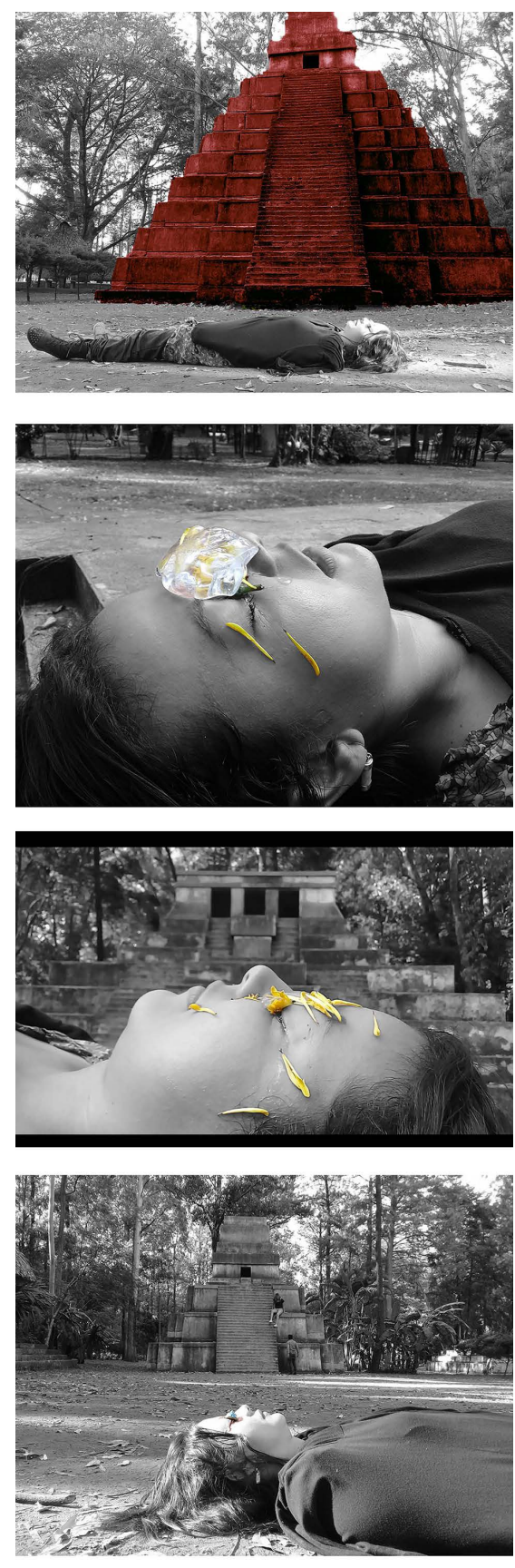

Fuente: Illimani de los Andes.

\section{Illimani de los Andes: tierra con apellidos}

La artista nicaragüense Illimani de los Andes, antropóloga con un máster en curaduría por la Universidad de Navarra, España, referencia que La Tierra, en tanto es el nombre del planeta. Simboliza el hábitat, con la singularidad que lo conocemos, pero que también desconocemos. Además, contiene todos los elementos para el desarrollo de la vida y en particular, de la especie humana.

Esta artista posee la concepción de que la tierra es la principal herramienta para resucitar, en tanto activa la energía ancestral al reiniciar el ciclo de la vida. Una de las inquietudes surgidas es ¿Si la tierra es la misma, cuál es el marcado interés suyo hacia la tierra de un cementerio? Responde:

La tierra del cementerio tiene elementos simbólicos, que al aplicarle ese apellido de "cementerio", nos incorpora desde el punto de vista fenomenológico la producción de memorias. La tierra del cementerio es sagrada, pues desde nuestra cultura cubre los cuerpos que, de forma natural se desintegran y vuelven al polvo (Quirós, 22 de agosto de 2020, párr. 6).

Otra de las interrogantes surgidas sobre su performance "Milagro de Dios" es ¿por qué usa la tierra de un cementerio?, específicamente del Milagro de Dios, ubicado en la periferia de Managua. Sobre esto, comenta: "[ahi] se enterraron a muchas víctimas de la violenta y desproporcionada respuesta gubernamental, contra civiles que protestaron y se manifestaron a partir de abril de 2018" (Quirós, 22 de agosto de 2020, párr. 8). 
En uno de sus primeros performances usa la masa de maíz, fruto de la tierra que enmienda el peso de la cultura que llevamos a espaldas. Comenta la artista:

El maíz era la base alimentaria prehispánica. Los monopolios intentan reemplazar los productos derivados. Alimentarnos del maíz es resistencia: Tortilla, fresco de chicha, tamales, yoltamales, güirila, indio viejo, sopa de queso, son algunos elementos básicos en la alimentación nicaragüense.... Las manos siembran maíz en tierra, así existe conexión cuerpo-maíz-tierra. En Mesoamérica la base alimenticia era el maíz, una fuente nutritiva hoy utilizada para diversidad de platillos, y la fusión ocasionada producto del sincretismo" (Quirós, 22 de agosto de 2020, párr. 12-15).

\section{Alessandro Valerio: tierra y agua}

El costarricense Alessandro Valerio (1992) es graduado de licenciatura en la Escuela de Artes y Comunicación Visual de la Universidad Nacional y cursa una maestría en Artes en la Universidad Autónoma de México. Para este artista la tierra es un material vivo, que le permite entenderla como objeto artístico y como sujeto, en tanto aporta en distintas formas al habitar del ser humano. Define varios frentes para la observación de esta materia, entre ellos, lo científico, ya que hoy en día los bordes se transparentan entre sí. Además, apunta que es importante tomar posiciones desde ambos puntos de vista, el científico y el artístico, para comprender la magnitud de la materia, que no es solo física sino también simbólica.

Alessandro comenta que la tierra aporta desde su funcionalidad, los cuales define como pequeños ritos que hoy en día se denominan procesos técnicos:

Por mencionar dos ejemplos, en la tierra se descomponen millones de microorganismos de montaña gracias a la humedad y nutrientes del suelo. Estos agentes, en procesos de fermentación, pueden convertirse en abonos. ya sea para el suelo agrícola o en sustentos que promuevan la biorremediación de los ríos, lagunas y lagos (Quirós, 18 de junio de 2020, párr. 3).

Una de las inquietudes para considerar al colectivo que se propone en este trabajo es preguntar si al trabajar con la tierra el artista observa lo espiritual. Ante la inquietud el artista responde: 
Tierra, maíz, agua: los elementos originarios del planeta

Reflexión

en el Arte contemporáneo mesoamericano

Imagen 6. Instalación en el Salón Nacional del Museo de Arte Costarricense "Mesa Maíz Pujagua" (2019)

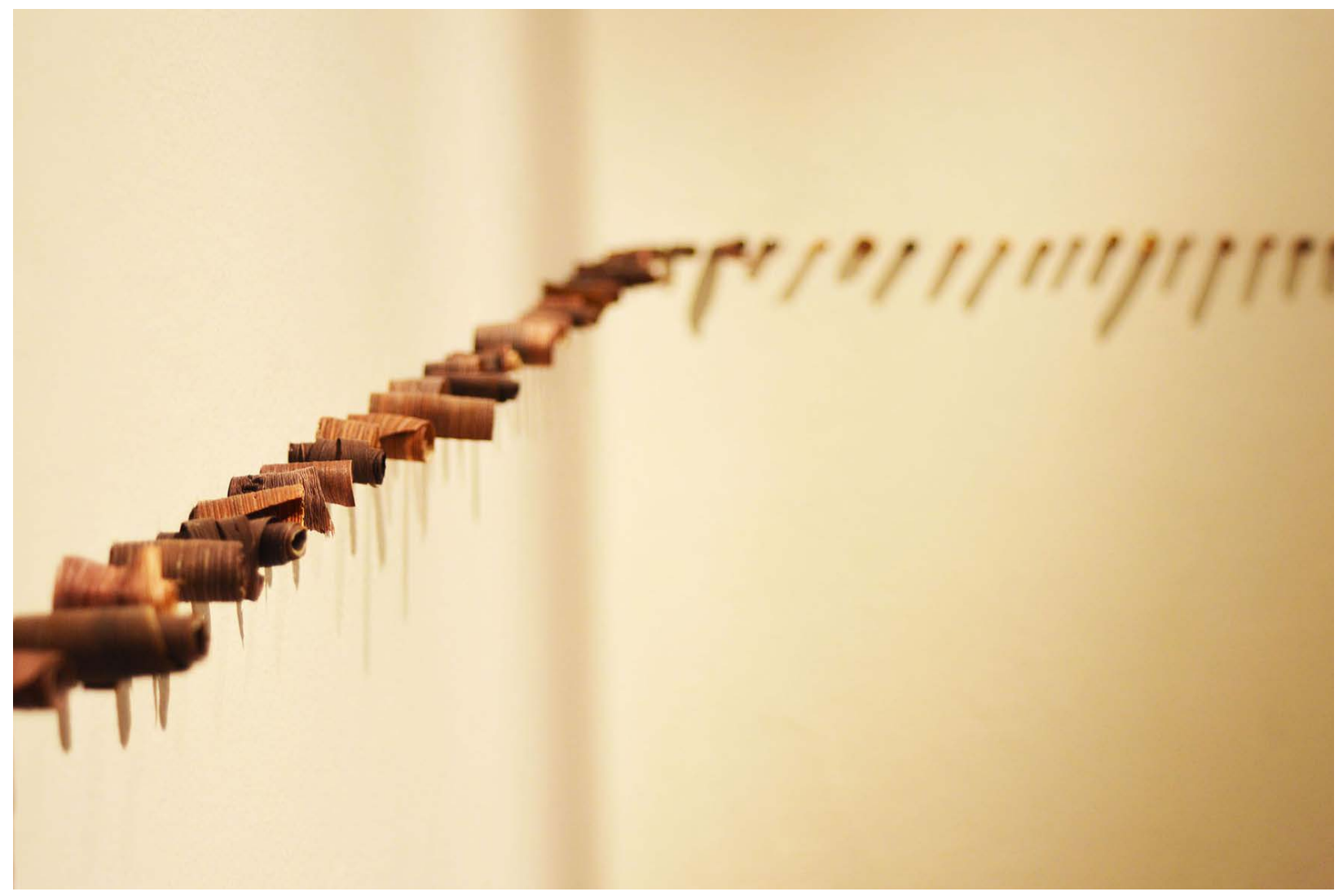

Fuente: Alessandro Valerio.

En el instante en que buscamos y otorgamos significados a la tierra, estamos inmersos en procesos existenciales/espirituales. La simple necesidad de generar preguntas y la dotación a los objetos de una carga simbólica para responderlas, es esa parte esencial que estructura todas las religiones y creencias culturales (Quirós, 18 de junio de 2020, párr. 10).

Valerio define como virtual dicha dimensión funcional de la tierra, lo que la vuelve apta para desarrollar proyectos artísticos. Considera la tierra dentro de su giro ontológico. Es decir, propone dejar de pensarla como objeto y más bien considerarla como un sujeto dador de vida. 


\section{Stephanie Williams: sin dejar de mirar la tierra}

El acercamiento a la artista me motiva preguntarle, ¿por qué no volvió a utilizar la pátina de lodo que nos recordaba el origen, lo sacro del suelo y subsuelo de La Tierra en sus anteriores instalaciones? En su respuesta ella argumenta que no lo ha dejado, y define que por su naturaleza, esos proyectos nunca terminan. Agrega que son abordajes que requieren apoyo de producción, para pensarlas desde un lugar específico, considerando el carácter efímero, pero que se pueden volver a construir (Quirós, 24 de julio de 2020).

En la entrevista realizada en el 2020, Stephanie Williams (1987) acota sobre su práctica actual que se ha trasladado y que desde hace algún tiempo realiza una serie de recorridos al espacio natural, donde hace observación y una especie de peregrinaje, pero que sigue viendo hacia la tierra. Al consultarle sobre sus instalaciones y si había algo más que interés por el uso del suelo patrio y un concepto que esclarecer e identificar al espectador Stephanie comenta:

Imagen 7. Instalación "Basamentos (ilustres) estacionados" (2014)

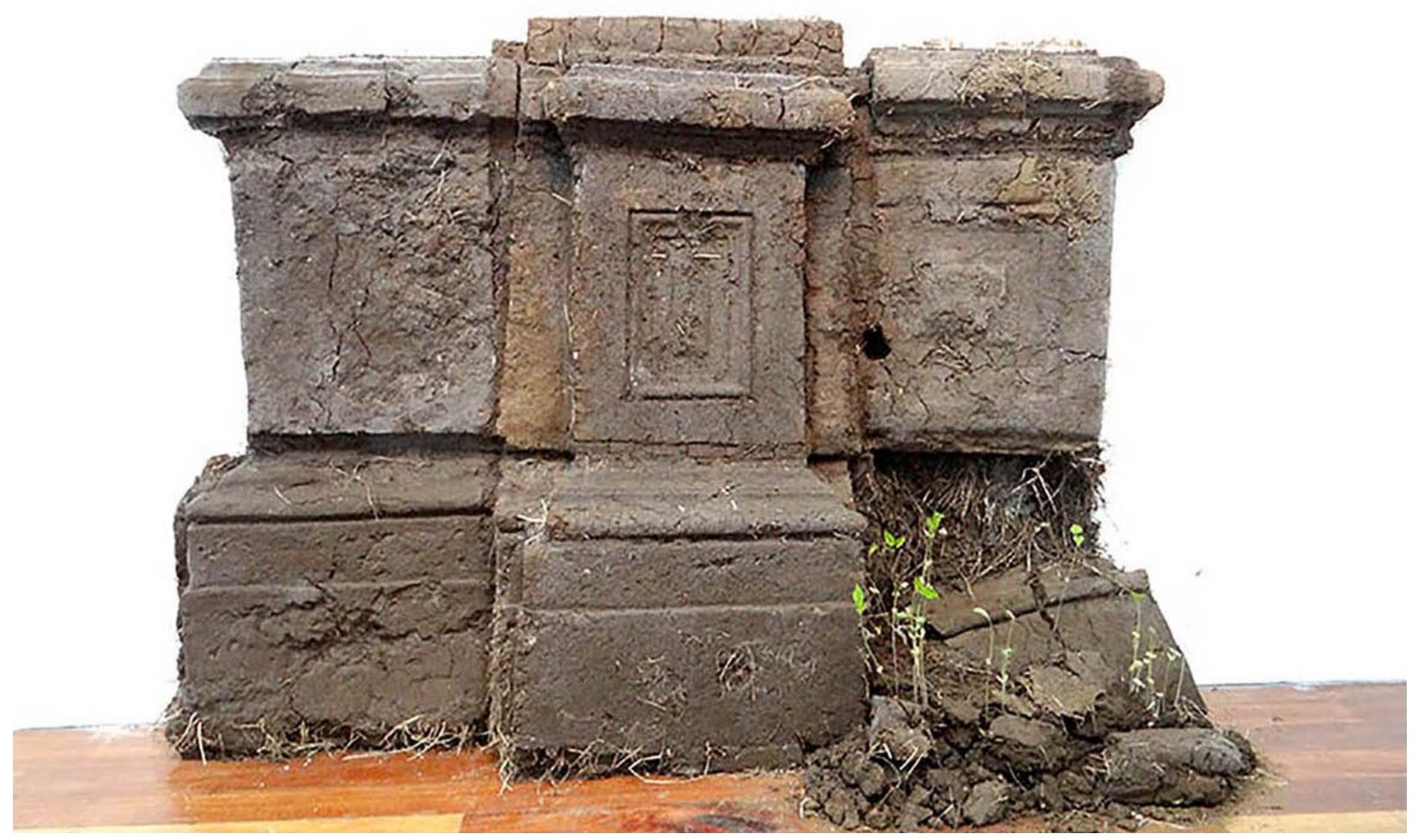

Fuente: Stephanie Williams.

ESCENA. Revista de las artes, 2021, Vol. 81, Núm. 1 (julio-diciembre), pp. 435-464 
Tierra, maíz, agua: los elementos originarios del planeta

Esas reflexiones vienen siempre de las formas de habitar el presente, inquietudes sobre las maneras de pensamiento, y, las acciones como reflejo de los procesos mediante los cuales se construyó la historia, trabajo con la ficción que de alguna u otra forma está implícita en esos procesos (Quirós, 2020, párr. 15).

Al considerar la relación de su obra con la espiritualidad, acota:

Me interesa el tratado sobre la tierra desde lo ancestral y las diferentes formas de habitarla, me interesan las voces disidentes, las historias no oficiales. La tierra como espacio movedizo, la exploración de espacialidades en flujos permanente de cambios, en las cuales el tiempo está conectado con el entorno. Cada tierra tiene signos de escritura, lenguajes que escriben los relatos de un lugar y de quienes lo habitan (Quirós, 2020, párr. 20-21)

Stephanie William entiende dicho sistema de pensamiento, como un lugar de resiliencia y de regeneración ante situaciones de crisis. Aclara: "Funcionan como narrativas estratificadas, reflexiones sobre la tierra y sus formas de habitarla, cercana a una arqueología imaginada, métodos que, desde formas transitorias construyen otras narrativas" (Quirós, 2020, párr. 22).

\section{Mariela Richmond: amor por el agro}

Mariela Richmond, docente de Artes de la Universidad de Costa Rica y artista visual, fundamenta su muestra de amor por la tierra y sus cultivos gracias a la influencia de la activista chilena Pancha Rodríguez. Existe una necesidad de enfocar la mirada a la tierra: brotar, seguir naciendo, seguir soñando, así como sanar el agro-tóxico y el prejuicio que se tiene hacia el trabajo con la tierra. Agrega que el enfoque no está exento de un abordaje político y artesanal alrededor de la siembra, el cual es un trabajo de hormiga, donde hay que replantear la noción de paso del tiempo, de organización, de responsabilidad y cuido.

Estos son grandes temas a revisar, en los procesos donde la tierra es como un gran laboratorio de percepción y donde muchas de sus fórmulas tradicionales ya están olvidadas:

[importa] archivarlos, documentar sus procesos y observar detalles, es ya en sí misma una labor de sistematización propia de un proceso artístico ... [Importa valorar] las voces de personas que trabajan en el campo, que han aprendido a leer 
Imagen 8. Instalación con productos agrícolas cultivados por la artista y un grupo de mujeres trabajadoras del campo (2020).

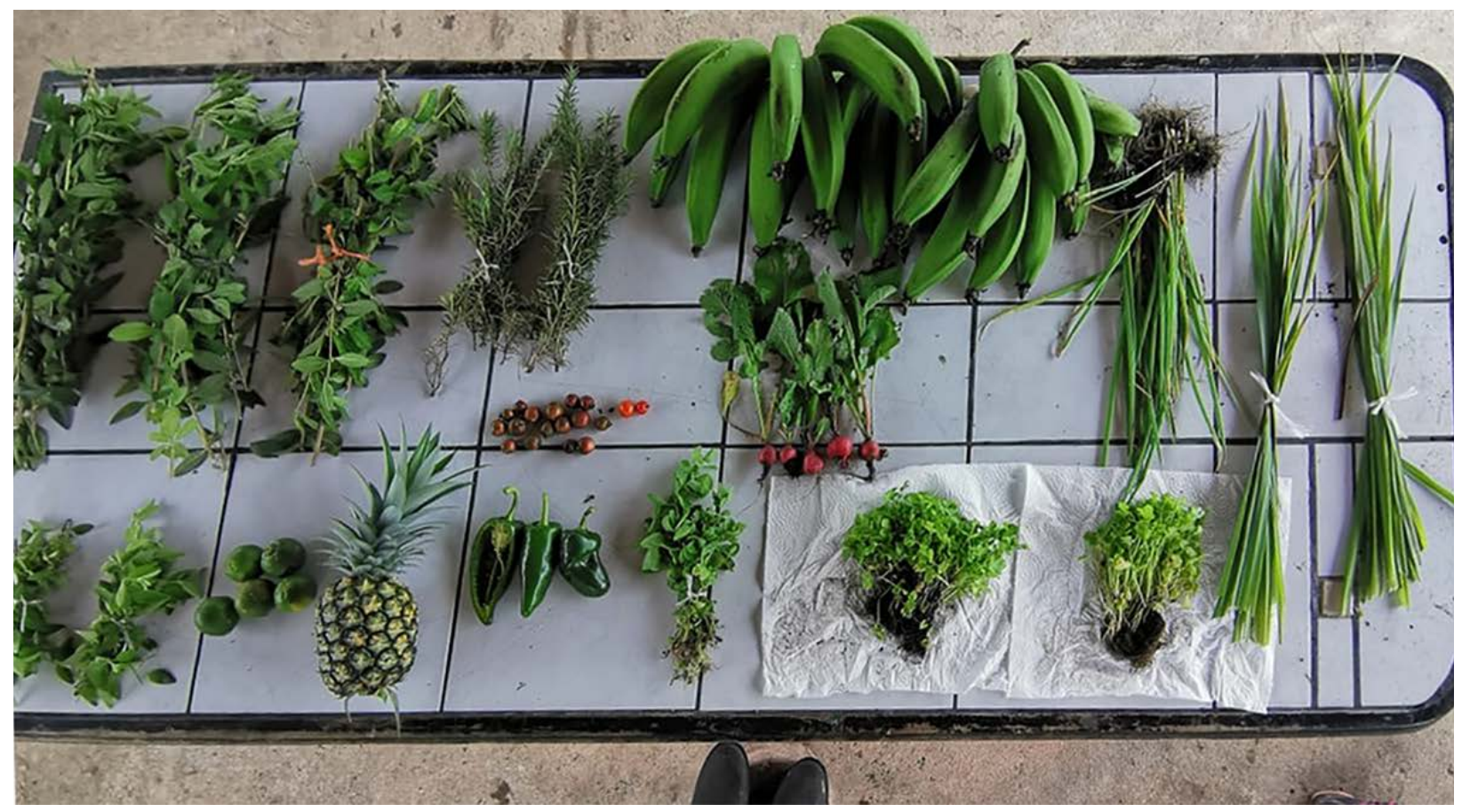

Fuente: Mariela Richmond.

las lunas, los colores, las formas... tiene una potencia política y un valor poético, que creo que apenas voy asimilando (Quirós, 3 de agosto de 2020, párr. 11-12).

Los importantes aportes de esta joven creadora costarricense me llevan a reflexionar sobre un pensamiento suyo, de naturaleza crítico:

Las cosas no andan bien con el arte, la educación, la cultura en general. La sostenibilidad, por ejemplo, es un tema fundamental, la noción de trabajo artístico, las reglas de la producción, me siento desgastada en esas estructuras, prefiero la hibridez, el poliamor investigativo, el intercambio, buscar otras formas de uso de nuestras herramientas artísticas, nuevas formas de economía (Quirós, 3 de agosto de 2020, párr. 24). 
Tierra, maíz, agua: los elementos originarios del planeta

Reflexión

en el Arte contemporáneo mesoamericano

\section{Yamil de la Paz García: poseer la tierra}

En el año 2020 fue publicada la muestra Tierra \& Arte Contemporáneo, proyecto del Museo del Pobre \& Trabajador, en la cual este artista y curador costarricense Yamil de la Paz (1978) expuso una pieza de la serie Memoria Histórica. Se trata de un conjunto de trabajos que hacen alusión a momentos históricos específicos que, ante el vertiginoso flujo de información al que tenemos acceso y el uso que hacemos de ella, suelen caer en el olvido.

La pieza exhibida "9॰09'00"N 83¹2'00"O 07.04.2016", da un paso más allá de la crítica al exceso mediático. Aborda una condición de la idiosincrasia costarricense: la desmemoria histórica. Por medio de un conjunto de coordenadas y una fecha, ha propuesto anteriormente una reflexión sobre la situación de los pueblos originarios y su lucha por defender lo poco que les queda (Quirós, 7 de agosto de 2020).

Yamil de la Paz, en la entrevista realizada el 7 de agosto de 2020, comenta que la tierra es hábitat, paisaje, alimento, curación, arte. Explica que el arte son códigos para comunicar. Pero sucede que, en ocasiones, la comunicación se queda en lo estético y requiere sintetizar lo que visualiza paisajes mentales, entendiéndose como espacios que posibilitan la generación de ideas a quienes los contemplan:

Dotar a la tierra de carga simbólica, que es algo que ha estado presente desde la prehistoria. Si consideramos estructuras como Stonehenge o las esferas de piedra del Valle del Diquís, el land art es un volver a la tierra. Ese retorno supone una reconexión. Y esa reconexión nos recuerda el vínculo que tenemos con el elemento. ... En la Historia del Arte existe la idea de que el artista es un narrador de los acontecimientos propios de su tiempo. En muchas ocasiones, las distintas manifestaciones artísticas han servido como referentes visuales de determinados hechos históricos. Me considero un heredero del legado de los artistas conceptualistas latinoamericanos de la segunda mitad del siglo XX, cuya obra propuso una nueva manera de entender la relación arte-sociedad" (Quirós, 7 de agosto de 2020, párr. 4-7).

\section{José Rosales: sin perder de vista la materia origen}

José Rosales (1993) es una voz muy crítica en el contexto del arte joven costarricense. Es graduado de la licenciatura en la Escuela de Arte y Comunicación Visual de la Universidad Nacional y tiene un alto perfil en espacios culturales del país. Su trabajo da impor- 
tantes logros en la evolución conceptual y material, ya que asimila nuevos materiales como las telas. Para la presente investigación, en una entrevista realizada en agosto del 2020 se le preguntó: ¿Cuál es tu preocupación estética respecto al uso de la tierra en el arte? y ¿Qué te daba esta materia tierra? José respondió:

Es materialmente muy atractiva y cambiaba de color con agua, todo eso la hacía muy interesante para trabajar. Después vienen las cosas menos prácticas, como su asociación con la cultura y el lenguaje, o lo que puede evocar en una pieza (Quirós, 19 de agosto 2020, párr. 4).

Para Rosales, la tierra resulta ser muy noble, por la enorme cantidad de significados, pero también aclara que a veces estos resultan conflictivos. Agrega: "Tiene esa particularidad de que no es para nada neutral, ya viene con muchas cargas de significado en el momento de usarla" (Quirós, 19 de agosto 2020, párr. 5).

Además, pregunté: "¿Te interesa solo la materia, la tierra, pero también sus frutos, como el maíz, que son un signo de cohesión en el arte de este istmo?" ante lo que José respondió: "Si he usado cosas de la tierra y productos de esta materia, pero he sido cauteloso en no proponerlos como articuladores de identidad, más allá de mis propias memorias" (Quirós, 19 de agosto 2020, párr. 8).

El artista señala algunos disensos, al comentar que él no trabaja la tierra con sus propias manos y que la realidad actual no podría estar más alejada del campo. Agrega que para cerrar este acercamiento a su trabajo lo que le interesan son los usos y las alternativas que les han dado otros artistas. Argumenta que no se trata de una estética de lo natural o lo agrícola propiamente dicho (Quirós, 19 de agosto 2020).

\section{Diana Barquero: importancia de los humedales}

Diana Barquero (1986), artista costarricense, aborda la tierra desde el humedal, el río, el océano, el lago afectados, en ocasiones, por la catástrofe y el desborde. Le interesa la tierra cuando es afectada por el agua y el agua afectada por la tierra. En la exposición de su proyecto de maestría en la Universidad Kunsthochschule, Berlín "Estrategias del espacio" delineó su intervención en el Humedal Nacional Térraba-Sierpe. 
Tierra, maíz, agua: los elementos originarios del planeta

Imagen 9. Instalación "Estudio de humedales de Sierpe" (2020)

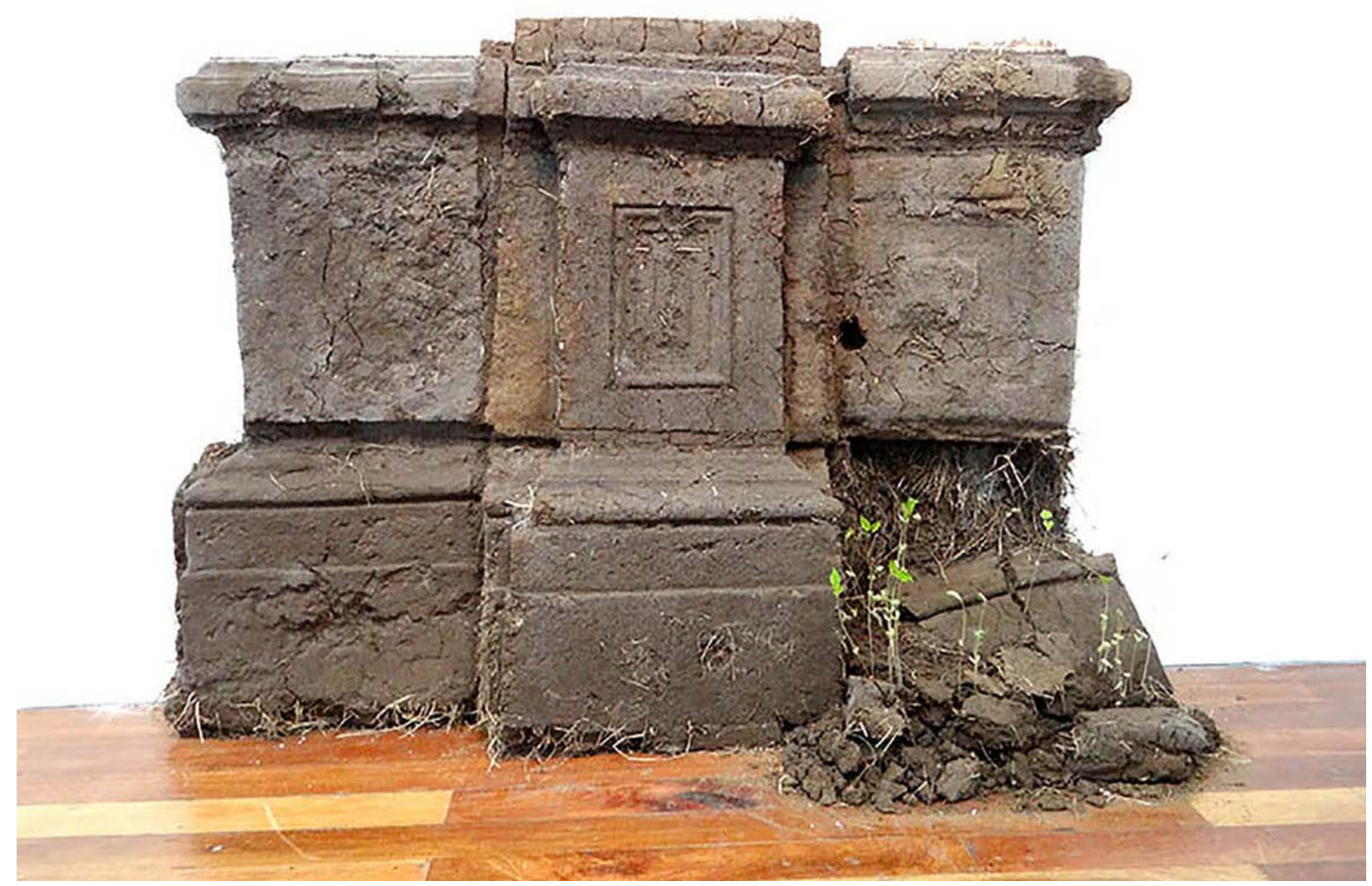

Fuente: Diana Barquero.

El eje central de la artista es el agua, materialidad que, para ella, transporta sustancias, las cuales son como un libro abierto, cuentan distintas historias sobre la construcción y los cambios en el paisaje del lugar. Además, aborda un fundamental anclaje que será tema del futuro, para el arte y otras disciplinas creativas. En el acercamiento que tuve con Diana Barquero, pregunté acerca del fenómeno de la contaminación con los agroquímicos, utilizados por la industria agrícola. El agua, para Diana, rompe con el imaginario existente sobre la idea de borde o límite entre zonas protegidas y zonas productivas y, por tanto, "Es el medio que nos puede ayudar a re-pensar y re-jerarquizar el lugar que ocupan estas materialidades en relación con la tierra, con nuestros cuerpos y los cuerpos de otros seres" (Quirós, 23 de agosto de 2020, párr. 7). 
A la artista, caracterizada por sus investigaciones con los fenómenos naturales, le interesa entender no solo los cambios en el uso de la tierra, sino también las luchas por los derechos de la tierra y de los trabajadores, así como los rastros de pesticidas están inscritos en los humedales. Sostiene que estos estudios están inscritos en los diferentes materiales y criaturas que mutan, se adaptan y se descomponen en el paisaje acuático. Se trazan en los movimientos del agua que transportan sus historias río arriba y abajo, hacia el pasado y el futuro.

Sintetiza que la contaminación con el uso de plaguicidas es un proceso lento, silencioso y escurridizo. Con respecto a las catástrofes que afectan los humedales, agrega:

No son necesariamente explosivas, ni implican una desaparición inmediata. La degradación es un proceso muy despacio, difícil de entender e imaginar. Sin embargo, los rastros aparecen en la tierra y el agua, penetrando en las capas del suelo e insertándose en los cuerpos de aquellos que viven cerca (Quirós, 23 de agosto de 2020, párr. 10).

Diana Barquero asume que trabajar con los elementos de agua y tierra aportan claridad a dicho carácter de mutación, de cambio y de resistencia:

He encontrado otras formas de entender el paso del tiempo, y también he encontrado la relación de los procesos de la tierra, con los procesos de los cuerpos. En este sentido, cuando estuve enfocada con el concepto de desborde, comprendí cómo ese desborde que podemos percibir en los ríos, volcanes y temblores, también se encuentra presente en los cuerpos y en los procesos sociales e históricos (Quirós, 23 de agosto de 2020, párr. 11).

\section{Recapitulación}

En estas reflexiones sobre elementos simbólicos o físicos de origen del planeta se externan aspectos fundamentales: la tierra como suelo y el agua como elemento dador de abundante vida han servido para sostener alcances de la teoría y práctica del arte contemporáneo en Mesoamérica. Apreciamos análisis críticos, pensamientos o focalizaciones de distintos artistas y países, para aunar un colectivo virtual que llamamos "Tierra". Digo virtual en tanto tiene el sustento del ente que lo promueve, el Museo de Pobre \& Trabajador. Este es un no espacio que junto con sus nociones de anonimato (Auge, 2000) observa el carácter de su inexistencia, noción de la antropología social. A su vez, es un espacio viven- 
Tierra, maíz, agua: los elementos originarios del planeta

Reflexión

en el Arte contemporáneo mesoamericano

cial donde se puede hacer mucho, en medio de su trama de redes sociales, con un carácter propio de las dinámicas de hoy, pero que requieren de pasión, amor por la investigación y la producción de cultura.

Algunos de los artistas y los insumos trabajados fundamentan reflexiones sociales, otras espirituales, en tanto el suelo es sacro, donado por el Creador para explotarlo y sacar frutos para alimentarnos en la vida cotidiana.

De esta forma, con este trabajo se dedujeron aspectos centrales para aunar a un colectivo que encuentre poesía: "La tierra es el vientre donde revienta el maíz" (Quirós, 22 de agosto de 2020, párr. 15) aprecia Illimani de los Andes. Por su parte, para Carlos Aguilar, la tierra es:

Isla, territorio, situación geográfica e intereses geopolíticos, conquistas, colonización, exterminio edénico, procesos de aculturación y transculturación, cultivo, esclavitud, sometimiento y lucha por la liberación nacional, régimen totalitario, comunismo, experimentación social, procesos de migración (Quirós, 11 de julio de 2020, párr. 10).

Mi connacional Alessandro Valerio explora la función de la tierra como suelo agrícola en su pieza "Maíz Pujagua" (2019). Además, relaciona la función de la tierra como sustento de procesos de biorremediación de ríos, lagos y humedales, lo que forma parte de las investigaciones de maestría que ejecuta en la Universidad Nacional Autónoma de México (UNAM). También, Stephanie Williams afirma que: "Son piezas efímeras pero que se pueden volver a construir". mi práctica se ha trasladado ... hago observación y una especie de peregrinaje, sigo viendo hacia la tierra". (Quirós, 24 de julio de 2020, párr. 14).

Desde su trabajo, Fernando Poyón explora eras, surcos, acomodamiento de objetos utilizados en los cultivos: el azadón, la sacha, pico y pala. Estas son herramientas físicas y el lenguaje de sus instalaciones, pero también herramientas de su pensamiento crítico, que rivalizan con lo que encasille, y/o demarque un territorio. Mientras que Ángel Poyón trabaja jícaros grabados con imágenes de aviones y autos, metáforas del mundo, como en Chi q'acho, Chi q'axe'el [a nuestra casa, a nuestra raíz] (2014). Estos son productos de la naturaleza, la cultura y descendencia, que serán leídos en busca de una conexión con el espíritu original. 
Para Mariela Richmond: "Hay un abordaje político y artesanal alrededor de la siembra, es un trabajo de hormiga donde hay que replantear la noción de paso del tiempo, de organización, de responsabilidad y cuido.... La tierra [es] un gran laboratorio de percepción" (Quirós, 3 de agosto de 2020, párr. 4) Por su parte, Yamil de la Paz García elabora una pieza de corte conceptual: cifra, código, localización o cuadratura geométrico-espacial que referían a una disputa de tierras. La pieza "909'00" $13^{\circ} 12^{\prime} 00^{\prime}$ O 07.04.2016" que como se mencionó antes aborda la desmemoria histórica y critica el exceso mediático. (Quirós, 7 de agosto de 2020).

José Rosales destaca una importante crítica a la metodología para aunar el colectivo: "No creo mucho en la articulación de la región a partir de esos signos, pero tampoco es que me oponga abiertamente a ello, solo prefiero hablar desde mi singularidad". (Quirós, 19 de agosto 2020, párr. 6). Por su parte, Diana Barquero señala respecto al uso de la tierra y el agua:

Son elementos que rompen con nuestra concepción del tiempo y de los ciclos. Sus ciclos son tan extensos y contienen en sí tantos cambios y respiraciones, que a veces nos resultan imperceptibles, hasta que violentamente vemos esos cambios manifestados (inundaciones, terremotos, entre otros) (Quirós, 23 de agosto 2020, párr. 11).

\section{A manera de cierre de este ensayo}

Observar la tierra, como materia, admite posturas, asumir o filtrar maneras de pensamiento crítico. Importa considerar la tierra como elemento a experimentar y a constatar lo que ocurre cuando se suma con otros elementos del planeta, como es el agua, de la cual se dice que conforma dos de las terceras partes del territorio terrestre.

Por un lado, fueron considerados simbolismos y mitos en la cultura para explorar tantos posibles lenguajes. Por otro lado, se contemplaron los abordajes de la tierra como propiedad, como bien tangible o el suelo patrio a defender ante los males contemporáneos o los de siempre: las migraciones, el filibusterismo moderno, la ensaña dominante del poder, el cual siempre intenta perpetuarse, al igual que lo hizo ayer. Nos detuvimos también a apreciar el agua, cuando interactúa con la tierra, o cuando se erosiona afectada por este preciado líquido; también cuando surgen otros paisajes, en esa perenne transformación del planeta. 
Estos abordajes catapultan a los artistas a investigar y experimentar sus lenguajes, como el arte y medio ambiente; arte y agro; arte y derecho o posesión de la tierra, y arte y tensiones sociales por el desplazamiento de las poblaciones originarias. Son alcances que cultivan nuevos escenarios y discursos muy actuales y que se proyectan a futuro, en este orden económico en crisis, afectado por la pandemia del COVID-19 y las intenciones hegemónicas. Las miradas a dichas problemáticas hoy en día son claves, incluso para comprender el arte de estos tiempos respecto al de ayer, cuando las conductas sociales exacerban y conducen a la migración y los desplazamientos, para buscar otra tierra donde mejorar nuestra condición humana. 


\section{Referencias}

Auge, M. (2000). Los no lugares. Espacios del anonimato. Barcelona: Gedisa. (Publicación original de 1992).

Bataille, G. (2005). Ero-tismo. Barcelona: Tusquets. (Publicación original de 1957).

Fallas, C. L. (1998). Mamita Yunai. San José, Costa Rica: Editorial Costa Rica. (Publicación original de 1941).

Ferrero, L. (2000). Costa Rica Precolombina. San José, Costa Rica: Editorial Costa Rica.

Herkenhoff. (2007). Rolando Castellón. San José, Costa Rica: Teorética.

Hoffmann, O. \& Morales, A. (2020). El territorio como recurso, movilidad y apropiación del espacio en México y Centroamérica. San José, Costa Rica: Flacso.

Museo de pobre. (junio 2020). Josué Orellana. Adobar la tierra. Muestra virtual. [Publicación digital]. Recuperado de https://issuu.com/luquiva/docs/josuue_orellana_ adobar_la_tierra_8a25adccbbca1c

Thomas, K. (1978). Diccionario del Arte Actual. Barcelona: Editorial Labor.

Pérez-Ratton, V. (2012). Travesía por un Estrecho Dudoso. San José: Teorética.

Quirós. L. F. (24 de agosto de 2019). Ángel y Fernando Poyón: Herramientas de poder. Wall Street International Magazine. Recuperado de https://wsimag.com/es/arte/56975-angel-y-fernando-poyon-herramientas-de-poder

Quirós, L. F. (11 de junio de 2020). Acecho de la sinapsis. Entrevista a Carlos Aguilar. Fatal: la fatalísima. Arboldardo en cuarentena. [Entrada de blog]. Recuperado de https://arboldardo.blogspot.com/2020/07/carlos-aguilar-asecho-de-la-sinapsis.html

Quirós, L. F. (22 de agosto de 2020). Culto a los ancestros. Entrevista a lllimani de los Andes.Wall Street International Magazine. Recuperado de https://wsimag.com/es/arte/63158-culto-a-los-ancestros

Quirós, L. F. (18 de junio de 2020). Alessandro Valerio: tierra como materia, simbolismo y significado. Fatal: la fatalísima. Arboldardo en cuarentena. [Entrada de blog]. Recuperado de https://arboldardo.blogspot.com/2020/07/alessandro-valerio-tierra-como-materia.html 
Tierra, maíz, agua: los elementos originarios del planeta

Quirós, L.F. (24 de julio de 2020). Stephanie Williams: reflexionar sobre la materia origen. Fatal: la fatalísima. Arboldardo en cuarentena. [Entrada de blog]. Recuperado de_https:// arboldardo.blogspot.com/2020/07/stephanie-williams-reflexionar-sobre-la.html

Quirós L.F. (3 de agosto de 2020). Mariela Richmond, Sacar frutos a la tierra. Fatal: la fatalísima. Arboldardo en cuarentena. [Entrada de blog]. Recuperado de: http://arboldardo.blogspot.com/2020/08/mariela-richmond-sacar-frutos-la-tierra.html

Quirós, L.F. (7 de agosto de 2020). Yamil de la Paz: Tierra. Fatal: la fatalísima. Arboldardo en cuarentena. [Entrada de blog]. Recuperado de: http://arboldardo.blogspot.com/2020/08/yamil-de-la-paz-garcia-tierra.html

Quirós, L.F. (19 de agosto de 2020). José Rosales. Alternativa de la tierra. Fatal: la fatalísima. Arboldardo en cuarentena. [Entrada de blog]. Recuperado de: http://arboldardo.blogspot.com/2020/08/jose-rosales-alternativas-de-la-tierra.html

Quirós, L.F. (23 de agosto de 2020). Diana Barquero: Agua y Tierra. "Si crees que puedes asir, piensa otra vez". Fatal: la fatalísima. Arboldardo en cuarentena. [Entrada de blog]. Recuperado de http://arboldardo.blogspot.com/2020/08/diana-barquero-agua-y-tierra.html 